\title{
IFLS C-Reactive Protein Data User Guide
}

Perry Hu, Elizabeth Henny Herningtyas, John Strauss, Eileen Crimmins, Jung Ki Kim, and Bondan Sikoki

RAND Labor \& Population

WR-675/7

October 2013

This paper series made possible by the NIA funded RAND Center for the Study of Aging (P30AG012815) and the NICHD funded RAND

Population Research Center (R24HD050906).

RAND working papers are intended to share researchers' latest findings and to solicit informal peer review. They have been approved for circulation by RAND Labor and Population but have not been formally edited or peer reviewed. Unless otherwise indicated, working papers can be quoted and cited without permission of the author, provided the source is clearly referred to as a working paper. RAND's publications do not necessarily

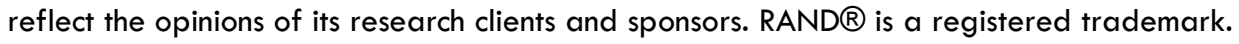




\title{
IFLS C-Reactive Protein Data User Guide
}

\author{
Perry $\mathrm{Hu}$ \\ University of California, Los Angeles \\ Elizabeth Henny Herningtyas \\ Gadjah Mada University \\ John Strauss \\ University of Southern California \\ Eileen Crimmins \\ University of Southern California \\ Jung Ki Kim \\ University of Southern California \\ Bondan Sikoki \\ Survey METER
}

September 2013 


\section{Preface}

This document describes the design and implementation of dried blood spot assays for high sensitivity Creactive protein (hs CRP) undertaken as part of IFLS4.

The Indonesia Family Life Survey is a continuing longitudinal socioeconomic and health survey. It is based on a sample of households representing about $83 \%$ of the Indonesian population living in 13 of the nation's 26 provinces in 1993. The survey collects data on individual respondents, their families, their households, the communities in which they live, and the health and education facilities they use. The first wave (IFLS1) was administered in 1993 to individuals living in 7,224 households. IFLS2 sought to reinterview the same respondents four years later. A follow-up survey (IFLS2+) was conducted in 1998 with $25 \%$ of the sample to measure the immediate impact of the economic and political crisis in Indonesia. The next wave, IFLS3, was fielded on the full sample in 2000. IFLS4 was fielded in late 2007 and early 2008 on the same 1993 households and their splitoffs; 13,535 households and 44,103 individuals were interviewed.

IFLS4 was a collaborative effort of RAND, the Center for Population and Policy Studies (CPPS) of the University of Gadjah Mada and Survey Meter. Funding for IFLS4 was provided by the National Institute on Aging (NIA), grant 1R01 AG026676, the National Institute for Child Health and Human Development (NICHD), grant 1R01 HD050764 and grants from the World Bank, Indonesia and AUSAID. Partial support for the validation and assessment of the CRP assay was provided by the National Institute on Aging, grant P30 AG017265. 


\section{Chronic Inflammation and CRP}

There is strong evidence supporting that chronic inflammation plays an important role in the process of aging and age-related diseases (Singh \& Newman 2011). Persistently elevated level of CRP, a biomarker for systemic inflammation, is associated with increased risk of cardiovascular disease, functional decline, and higher mortality in older adults. Therefore, DBSbased CRP assay has been increasingly incorporated into community-based surveys. Compared to venous blood samples, DBS specimens are easier to collect, and do not need to be processed and frozen immediately.

\section{Method of DBS-based CRP Assay}

For the DBS-based CRP assay, IFLS collaborated with the laboratory at the Clinical Pathology Department, Gadjah Mada University, Yogyakarta, Indonesia. This laboratory is part of the network that is performing DBS-based assays for the World Health Organization (WHO)'s Study on Global Aging and Adult Health (SAGE) project. The laboratory head, Dr. Henny Herningtyas, was trained for DBS-based assays, including CRP, in a training course organized by the SAGE. She participated and supervised the laboratory work for IFLS. Three technicians worked under her, while her laboratory measured CRP levels on IFLS specimens.

CRP concentrations in DBS specimens were measured using validated ELISA method (McDade et al, 2004). Optic densities (OD) of all samples were measured using an automated ELISA reader. The detection limit of this CRP assay is $0.028 \mathrm{mg} / \mathrm{L}$. The intra-assay coefficient of variation $(\mathrm{CV})$ is reported to be $5.8 \%$ and the inter-assay $\mathrm{CV}$ is $8.2 \%$ (McDade et al, 2004). The IFLS laboratory used the reagents from the same manufacturers specified in the assay protocol. Some of the reagents were not available locally. Therefore, we worked with the WHO 
(SAGE project) to purchase and ship these reagents into Indonesia, under shipping conditions specified by the manufacturers.

\section{Validation and Quality Control of DBS-based CRP Assay}

$\underline{\text { 1. Pretest }}$

Venous and DBS specimens for the pre-test were collected from 67 volunteers who were recruited through the USC/UCLA Center on Biodemography and Population Health (CBPH). Serum samples were sent to the laboratory at Department of Laboratory Medicine, University of Washington (UW), for high-sensitivity CRP (hsCRP) assay (Laboratory director: Alan Potter, $\mathrm{PhD}$ ). Two DBS cards were collected from each volunteer via direct finger prick, with two blood spots on each card. One set of DBS cards were sent to UW for DBS-based hsCRP assay, while the other set were sent to the laboratory at Gadjah Mada University, Indonesia. Validation samples for both laboratories were shipped with dry ice. Duration of shipment to Indonesia was approximately 48 hours.

Fifteen validation samples and 79 IFLS study samples were measured for CRP levels during the pretest, which was conducted in December of 2011 and lasted for 5 days. Fourteen validation samples had DBS-based CRP values from the ILFS laboratory as well as both DBSbased and serum-based values from UW. For calculation purpose, results with undetectable CRP levels were assigned a value of $0.001 \mathrm{mg} / \mathrm{L}$. The correlation coefficients for CRP results were 0.98 between the IFLS DBS and UW DBS, 0.97 between the IFLS DBS and serum, and 0.97 between the UW DBS and serum. The average differences were $0.11 \mathrm{mg} / \mathrm{L}$ (standard deviation: $0.54 \mathrm{mg} / \mathrm{L}$ ), $0.14 \mathrm{mg} / \mathrm{L}$ (standard deviation: $0.60 \mathrm{mg} / \mathrm{L}$ ) and -0.21 (standard deviation: 0.61 
$\mathrm{mg} / \mathrm{L}$ ), respectively. IFLS also had repeated measurements of CRP levels on 10 samples from study participants. The correlation coefficient between the test-retest results was 0.998 .

\section{Ongoing assay quality control with validation samples}

The IFLS research team, led by Dr. Peifeng (Perry) Hu, established regular communication with the laboratory and reviewed the CRP results from study samples on a biweekly basis. All CRP standards, controls, and study samples were measured in duplicate. Individual samples with duplicate $\mathrm{CV}$ above $10 \%$ were re-tested, unless both concentrations were less than $0.2 \mathrm{mg} / \mathrm{L}$. When inter-assay variability exceeded $10 \%$, which was based on control values, the entire microwell plate would be rerun.

During the testing of study samples, IFLS included 8 validations on every $40^{\text {th }}$ microplate, approximately every 1,500 study samples: A total of 48 validation samples were measured over a 6-month period. Using serum-based CRP levels as the gold standard, the results from IFLS and UW were comparable. For each batch of 8 validation samples, the correlation coefficients between DBS-based and serum-based values were all above 0.95 in both laboratories.

Summary statistics from the DBS CRP readings from both the Indonesian and UW labs are shown in Table 1. Serum equivalents are also shown as is the serum-based readings from the UW lab. Regressions of the UW results on the Indonesian lab results for DBS serum equivalents and Bland-Altman plots are shown in Figure 1. Figure 2 shows the same for the Indonesian DBS serum equivalents and the UW serum samples and Figure 3 for the UW serum samples and the UW DBS serum equivalents. The $\mathrm{R}^{2} \mathrm{~s}$ are all above 0.90 , and the plots, including the Bland Altman plots look good. 
The results from validation samples have showed that DBS-based CRP values from IFLS had excellent correlations with serum-based values and/or DBS-based results from UW. The IFLS laboratory was able to maintain its assay quality during the testing of actual study samples.

\section{Sampling for CRP}

Blood was taken on all individuals with AR01i==1 (who would get individual interviews) over 1 year old living in a random half of IFLS stem households; where a stem household is defined as an IFLS1 household and all of its splitoffs. In US2 there is an indicator variable which informs us whether a respondent had blood taken. Some 20,000 individuals had finger prick blood samples taken and dried blood spot cards made. Cost did not allow for all of these samples to be analyzed, the ones not analyzed are stored at Survey Meter in a deep freezer at -20C. To choose which samples would be assayed for CRP, the following algorithm was used:

1. All persons aged 50 years and over with DBS samples were chosen.

2. All persons in the same household (nuclear, not stem) as the 50 year olds and were chosen-these 2 criteria gave us 7,888 potential samples

3. A random sample of 2,200 persons under age 50 , stratified by age, who live in the same stem households as the $50+$ respondents chosen in 1.
a. $\quad 100$ aged $1-4$
b. 500 aged $5-14$
c. 1,452 aged $15-39$
d. 148 aged $40-49$

\section{CRP data file}

There are 9,945 observations with CRP data. The number of observations is a little less than the number sampled because some sampled respondents with DBS had unusable blood spots, generally because the circles were not filled enough to take punches for the assay. The data file, crp_public_use.dta (the STATA file), has the following variables: 
Mean_WB_conc = MEAN CRP concentration from 2 duplicate samples from the same specimen (if available)

Mean WB concn impute = Mean CRP concentration with imputations for undetectable values Mean_serum_eq_conc $=$ Mean serum equivalent CRP concentration from 2 duplicate samples from the same specimen

Mean_serum_eq_conc_impute $=$ Mean serum equivalent CRP concentration with imputed values.

WB_impute = binary indicator if WB value is imputed

Serum_impute $=$ binary indicator is serum value is imputed

Pct_cv $=$ Coefficient of variation of the two readings per observations without imputation. High values (over 10\%) were used as one criterion to decide if a re-test was needed.

IDRTK $=$ Enumeration area code

HID $=$ Household id

PID = person id within the household

PIDLINK $=$ Person id used to link across waves and across modules

Some $43 \%$ of the samples had very low values that were undetectable. These are indicated by

wb_impute and serum_impute. These values should NOT be assumed to be missing or invalid,

they are just very low. We imputed them as 0.1 for mean WB and 0.2 for mean serum and added those to the * impute variables. Summary statistics are shown in Table 2.

Figures 4-11 plot the distributions of the CRP values and serum equivalents, both unlogged and logged, without and with imputations. Without imputations the logged distributions look close to symmetric. There is a reasonable spread in the distributions allowing for analysis by users. 
Table 1 Indonesia and UW Validation Samples Summary Statistics

\begin{tabular}{|l|c|c|c|c|c|c|}
\hline & $\mathrm{N}$ & Mean & SD & Min & Max & Median \\
\hline DBS_INDONESIA & 46 & 1.31 & 1.28 & 0.0005 & 6.026 & 0.95 \\
\hline DBS_SERUM_EQUI_INDONESIA & 46 & 2.62 & 2.56 & 0.001 & 12.052 & 1.89 \\
\hline DBS_UW & 46 & 2.64 & 2.54 & 0.13 & 9.38 & 2.01 \\
\hline DBS_UW_SERUM_EQUI & 46 & 2.41 & 2.17 & 0.11 & 7.90 & 1.70 \\
\hline SERUM_UW & 46 & 2.34 & 2.42 & 0.00 & 9.5 & 1.50 \\
\hline
\end{tabular}


Figure 1 Regression and Bland-Altman Plot of UW Serum Equivalent on IFLS Serum Equivalent-Validation Samples

\begin{tabular}{|c|c|}
\hline$N=46$ & \\
\hline Fouation & DBS_UW_Serum_Equi $=0.29868+$ \\
\hline $\mathrm{R}^{2}$ & .9009 \\
\hline
\end{tabular}

CRP, mg/L (Plasma Eq-Mean)
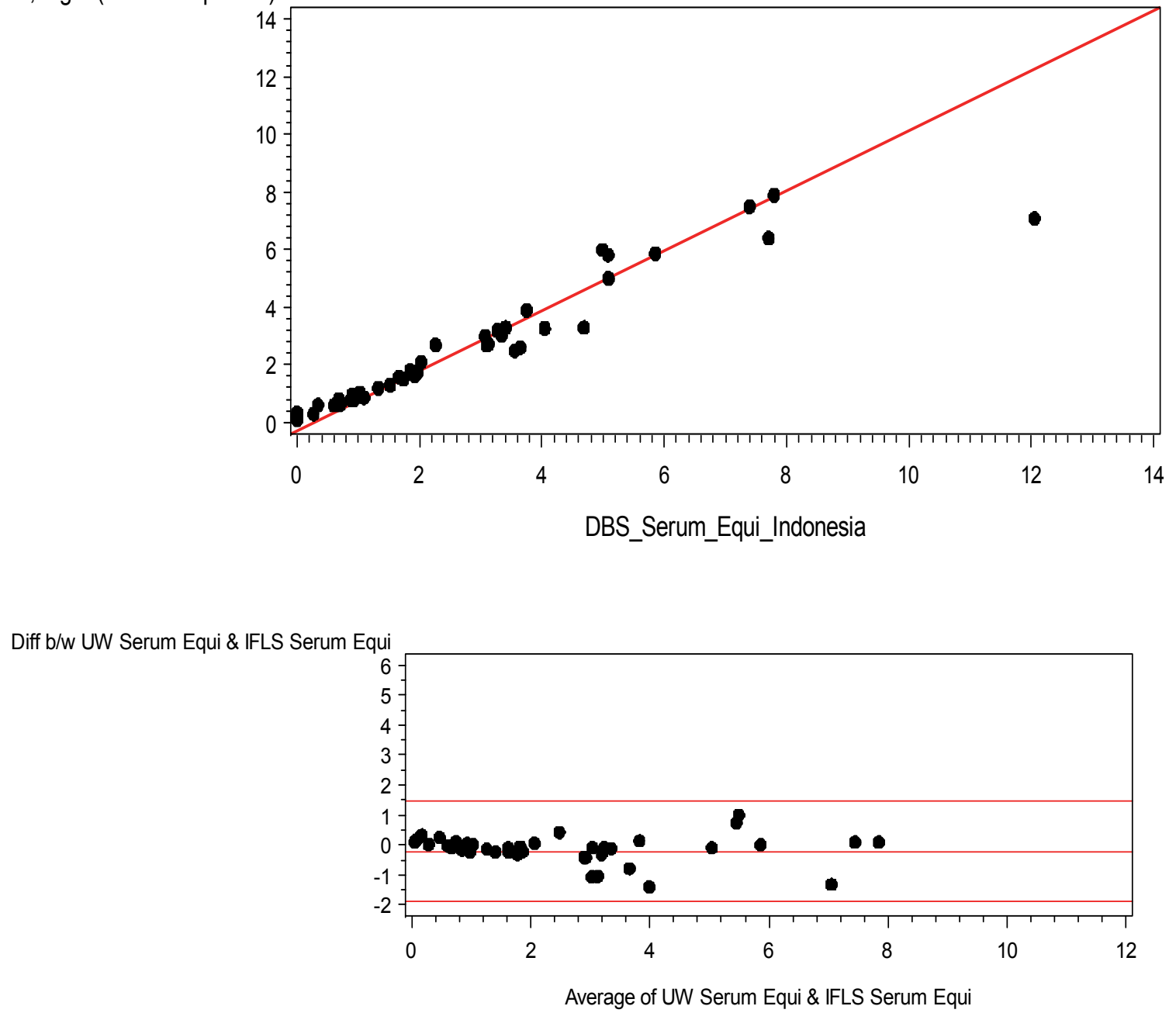

Bland-Altman Plot

Figure 2 Regression and Bland-Altman Plot of UW Serum on IFLS Serum Equivalent 


\section{Validation Samples}

\begin{tabular}{|c|c|}
\hline $\mathrm{N}=46$ & \\
\hline Equation & Serum_uw $=-0.06608+0.91602 * D B S \_S e r u m \_E q u i \_I n d o n e s i a$ \\
\hline $\mathrm{R}^{2}$ & .9392 \\
\hline
\end{tabular}
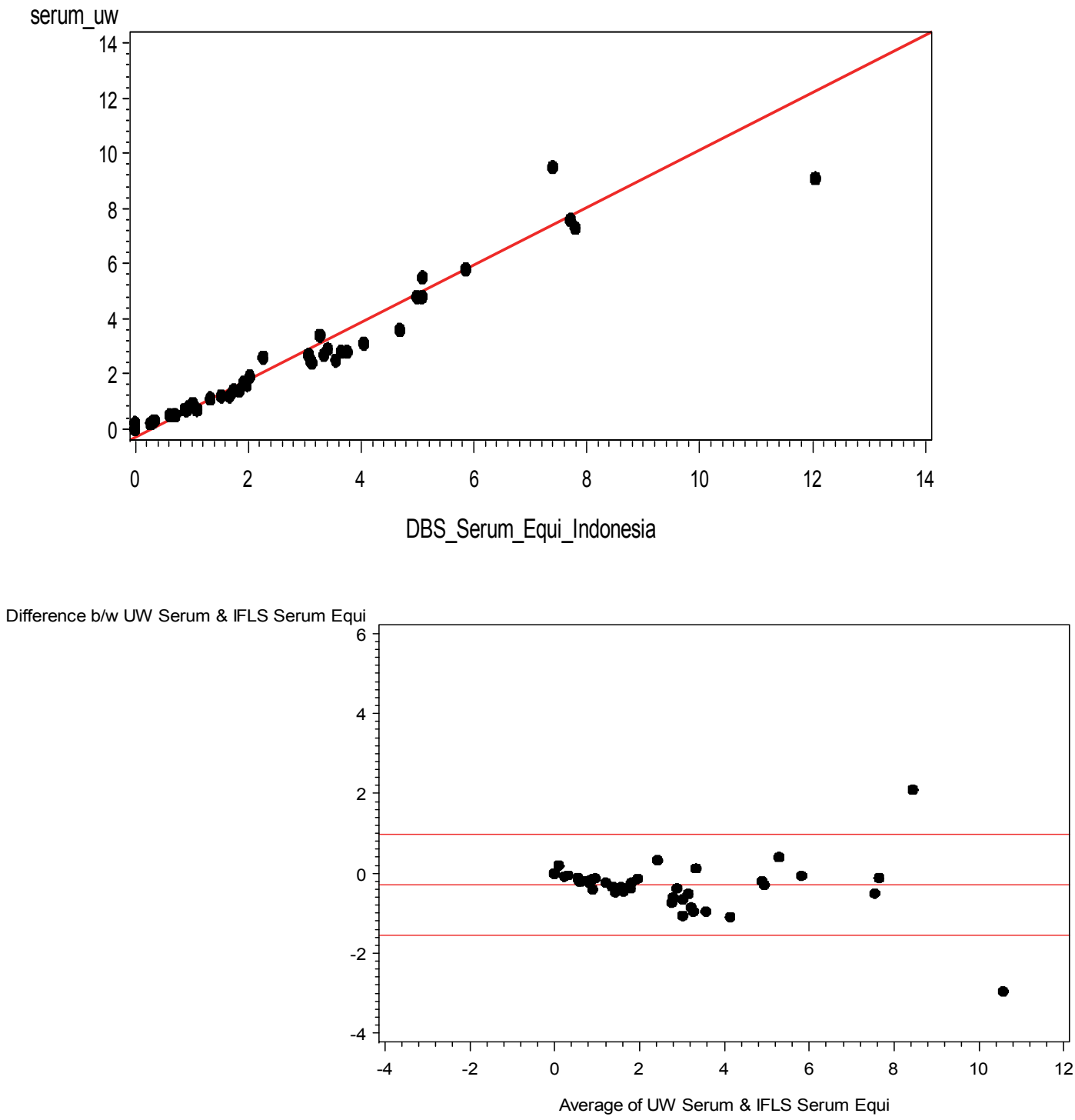

Bland-Altman Plot 
Figure 3 Regression and Bland-Altman Plot of UW Serum on UW Serum Equivalent Validation Samples

\begin{tabular}{|c|c|}
\hline $\mathrm{N}=46$ & \\
\hline Equation & Serum_uw $=-0.27856+1.08459 *$ DBS_UW_Serum_Equi \\
\hline $\mathrm{R}^{2}$ & .9480 \\
\hline
\end{tabular}
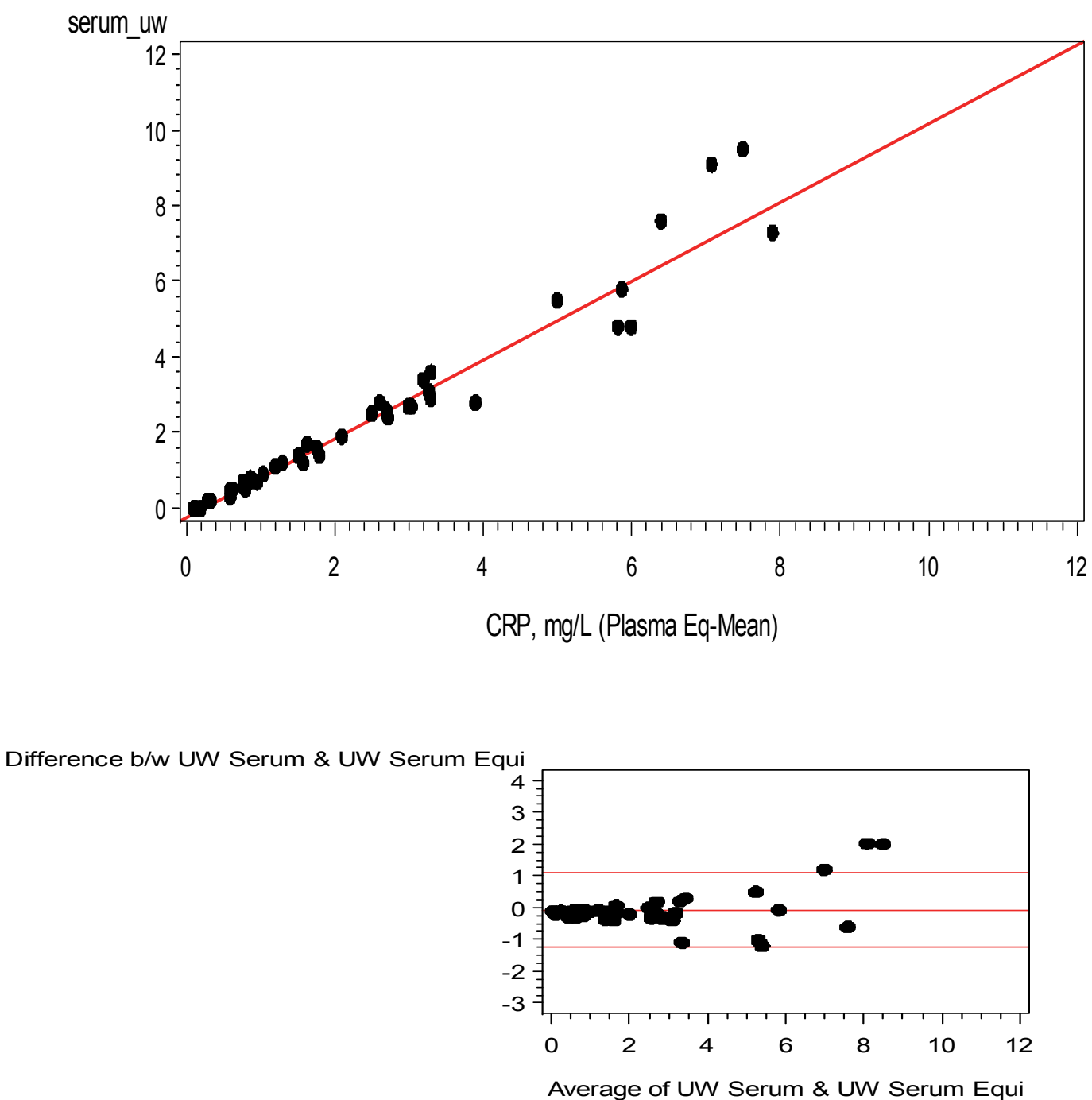

Bland-Altman Plot 
Table 2 Summary Statistics for CRP Values

\begin{tabular}{|l|c|c|c|c|c|}
\hline & $\mathrm{N}$ & $\begin{array}{c}\text { Mean } \\
(\mathrm{mg} / \mathrm{L})\end{array}$ & Std Dev & Min & Max \\
\hline MEAN_WB_CONC & 5,680 & 0.9880184 & 1.3984586 & 0.04 & 15.6645 \\
\hline MEAN_WB_CONC_IMPUTE & 9,941 & 0.6073880 & 1.1447642 & 0.04 & 15.6645 \\
\hline MEAN_SERUM_EQ_CONC & 5,659 & 1.9753895 & 2.7950272 & 0.08 & 31.3290 \\
\hline MEAN_SERUM_EQ_CONC_IMPUTE & 9,941 & 1.2124317 & 2.2844506 & 0.08 & 31.3290 \\
\hline
\end{tabular}


Figure 4 Mean CRP distribution-without imputations

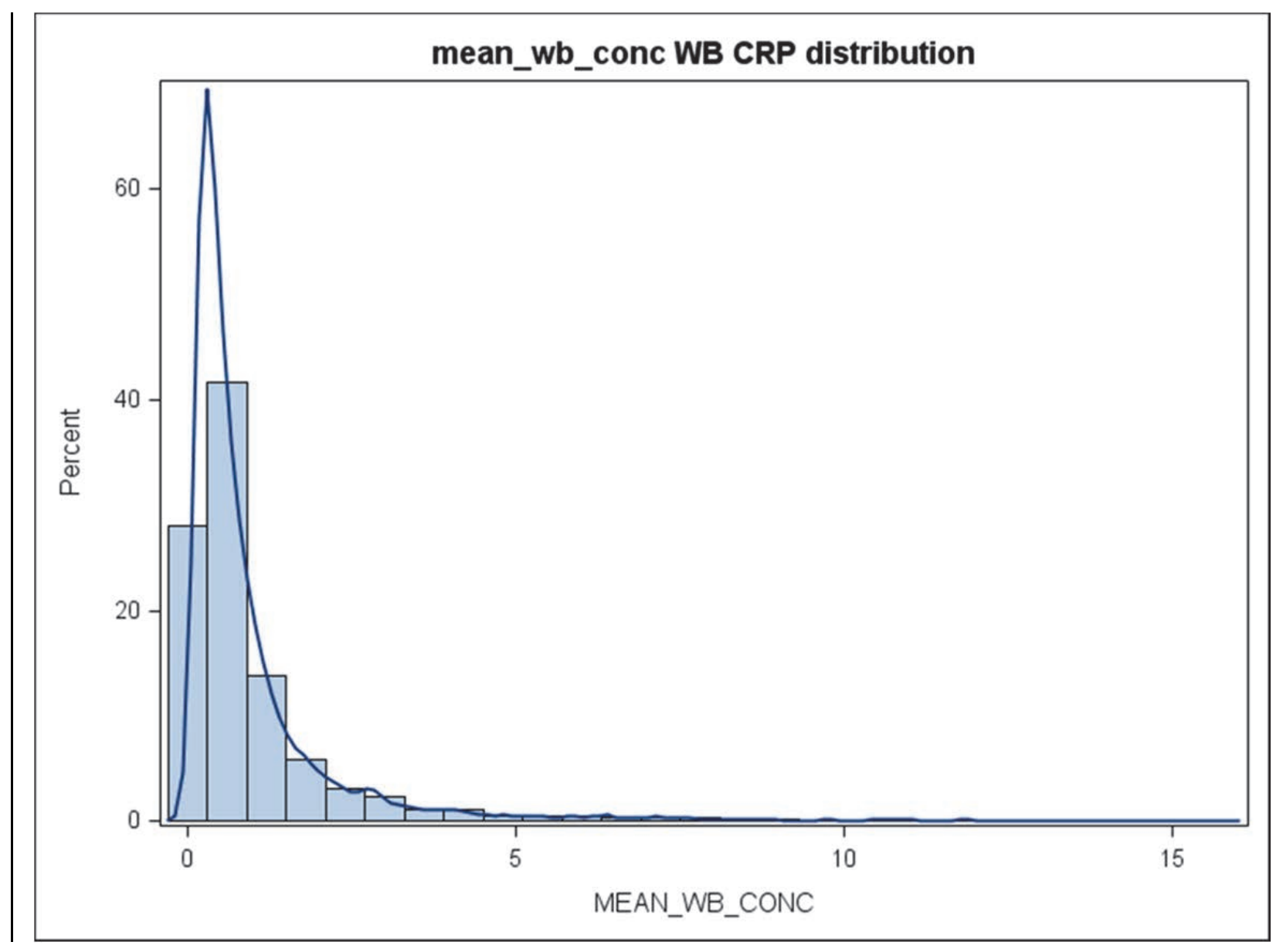


Figure 5 Logged mean CRP distribution-without imputations

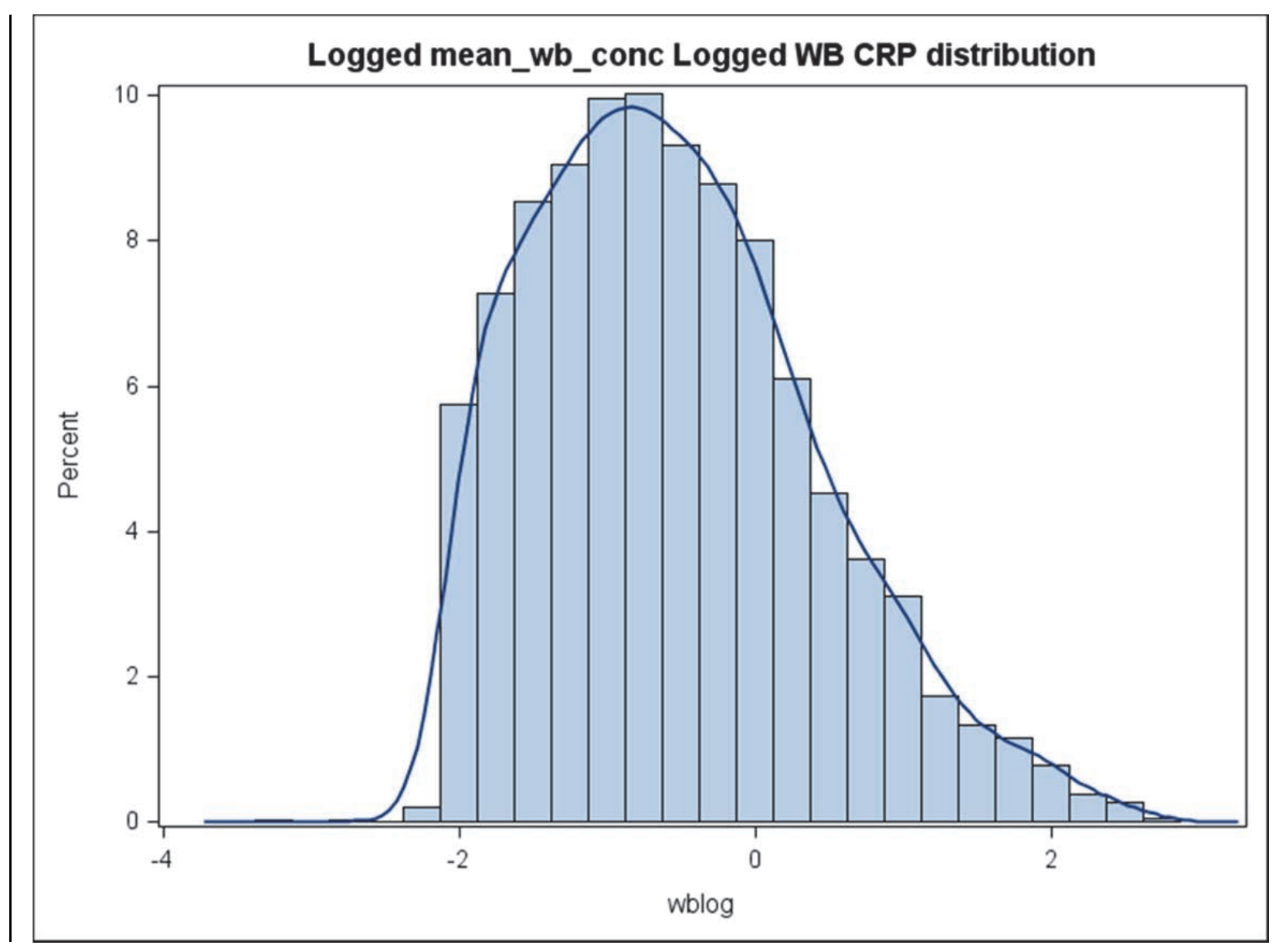


Figure 6 Mean CRP distribution-with imputations

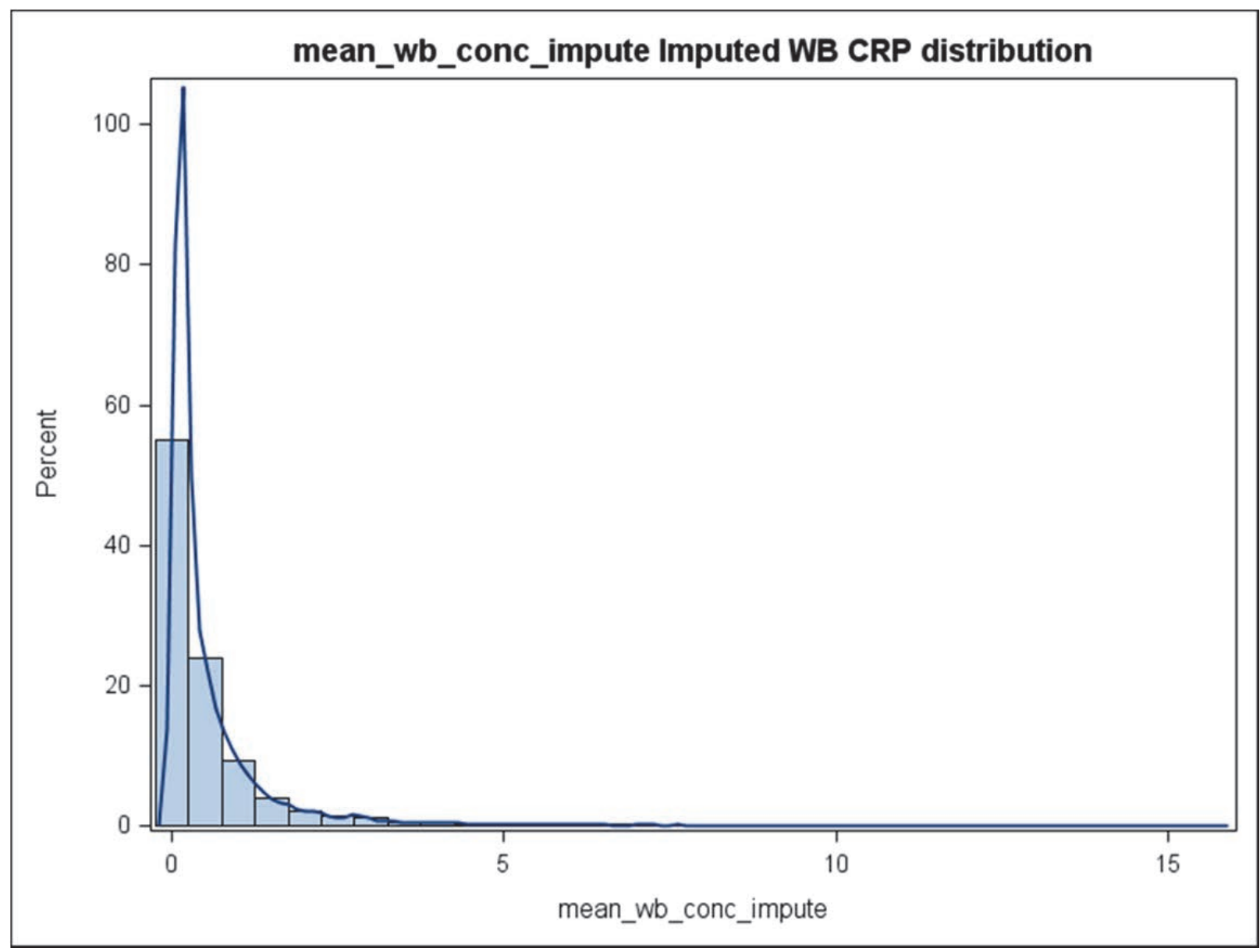


Figure 7 Mean Logged CRP distribution-with imputations

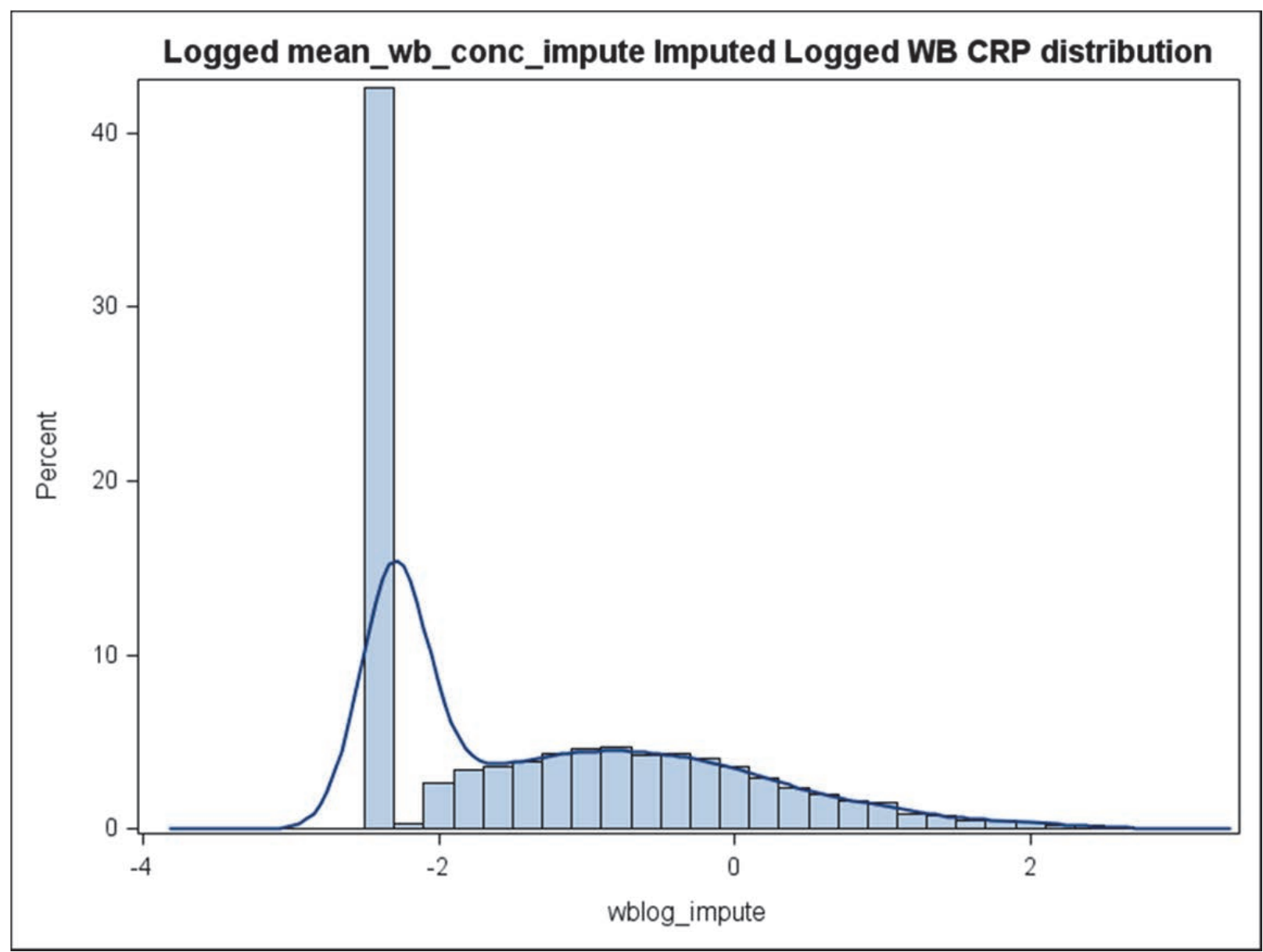


Figure 8 Mean serum-equivalent CRP distribution-without imputations

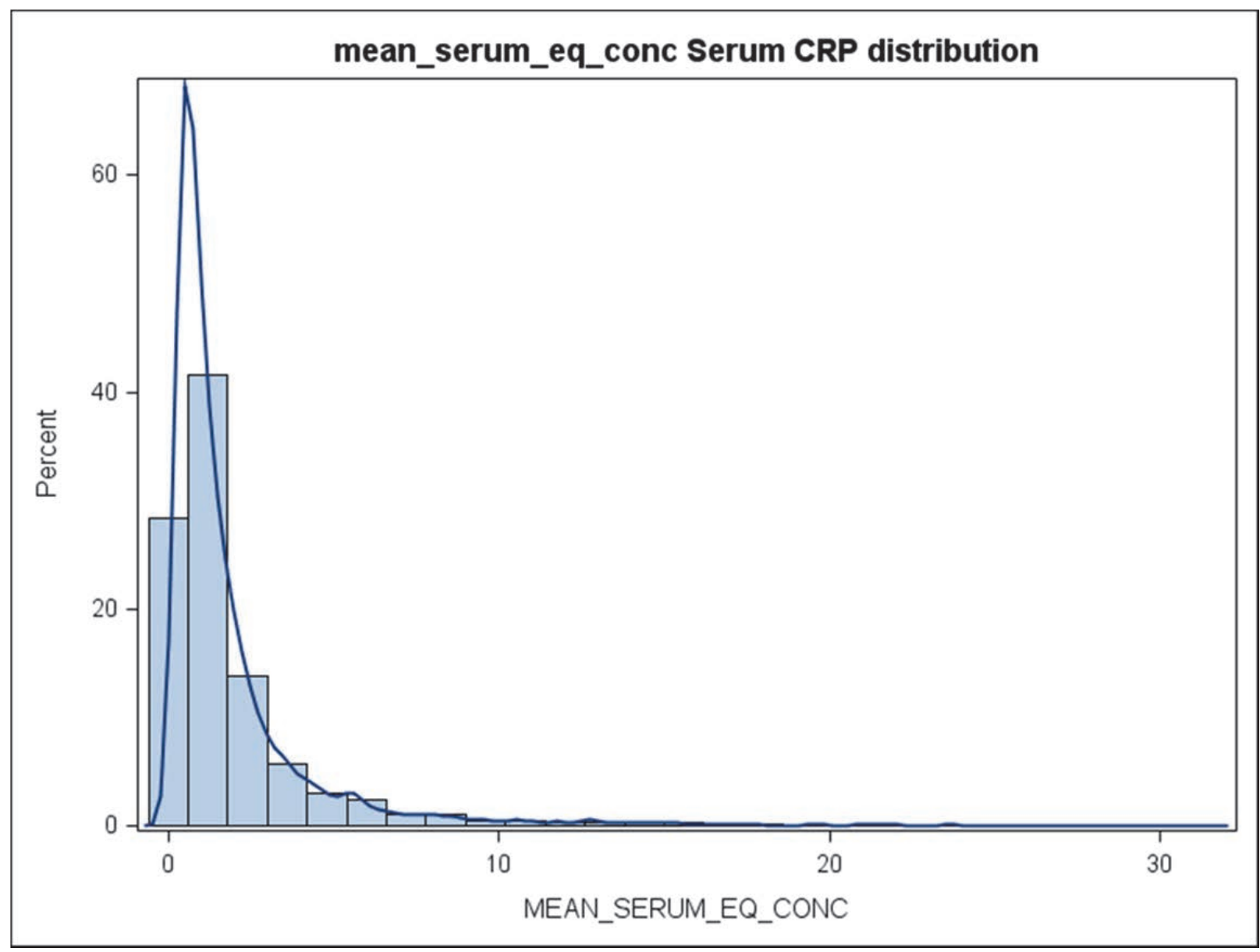


Figure 9 Mean logged serum-equivalent CRP distribution-without imputations

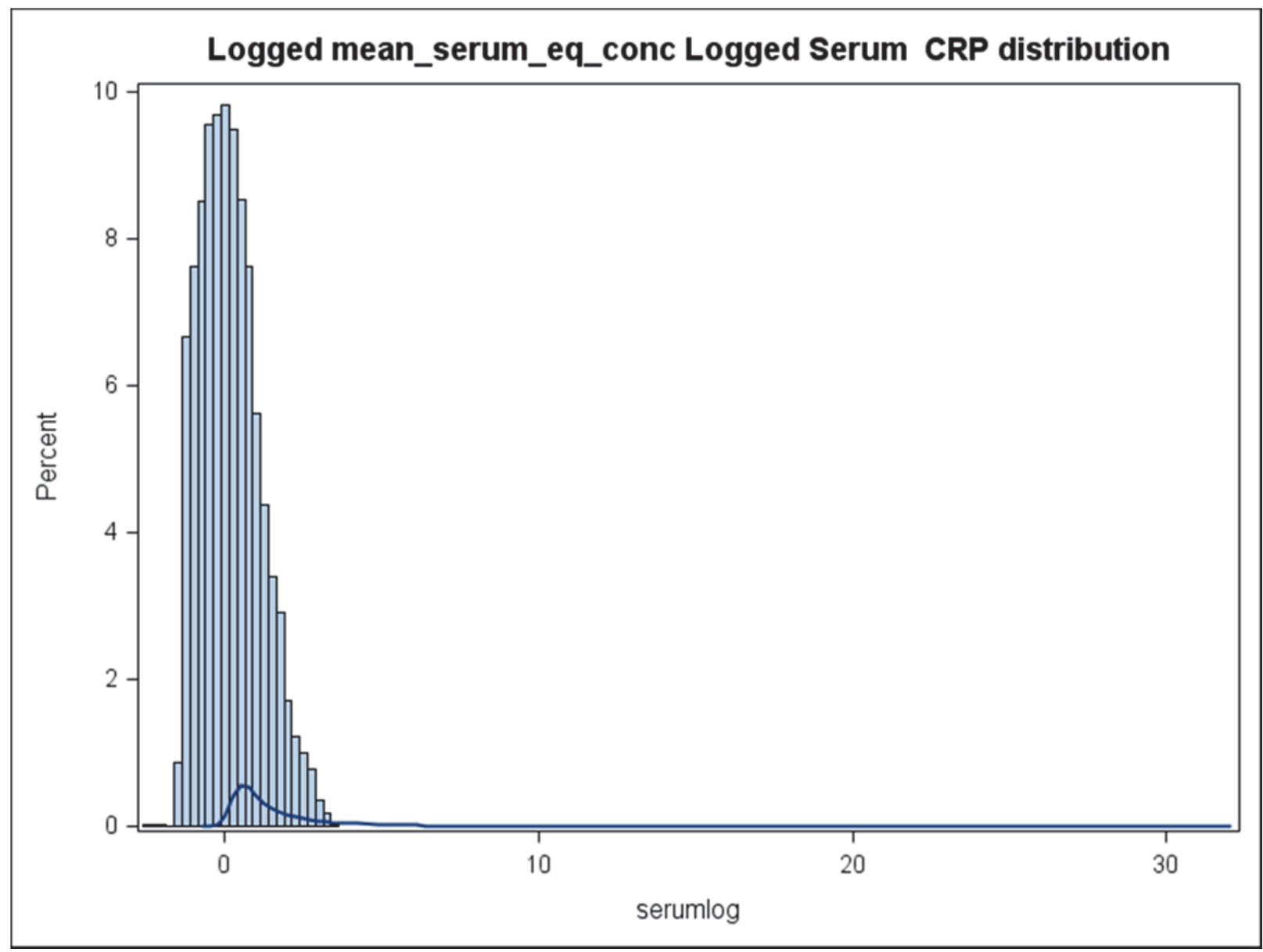


Figure 10 Mean serum-equivalent CRP distribution-with imputations

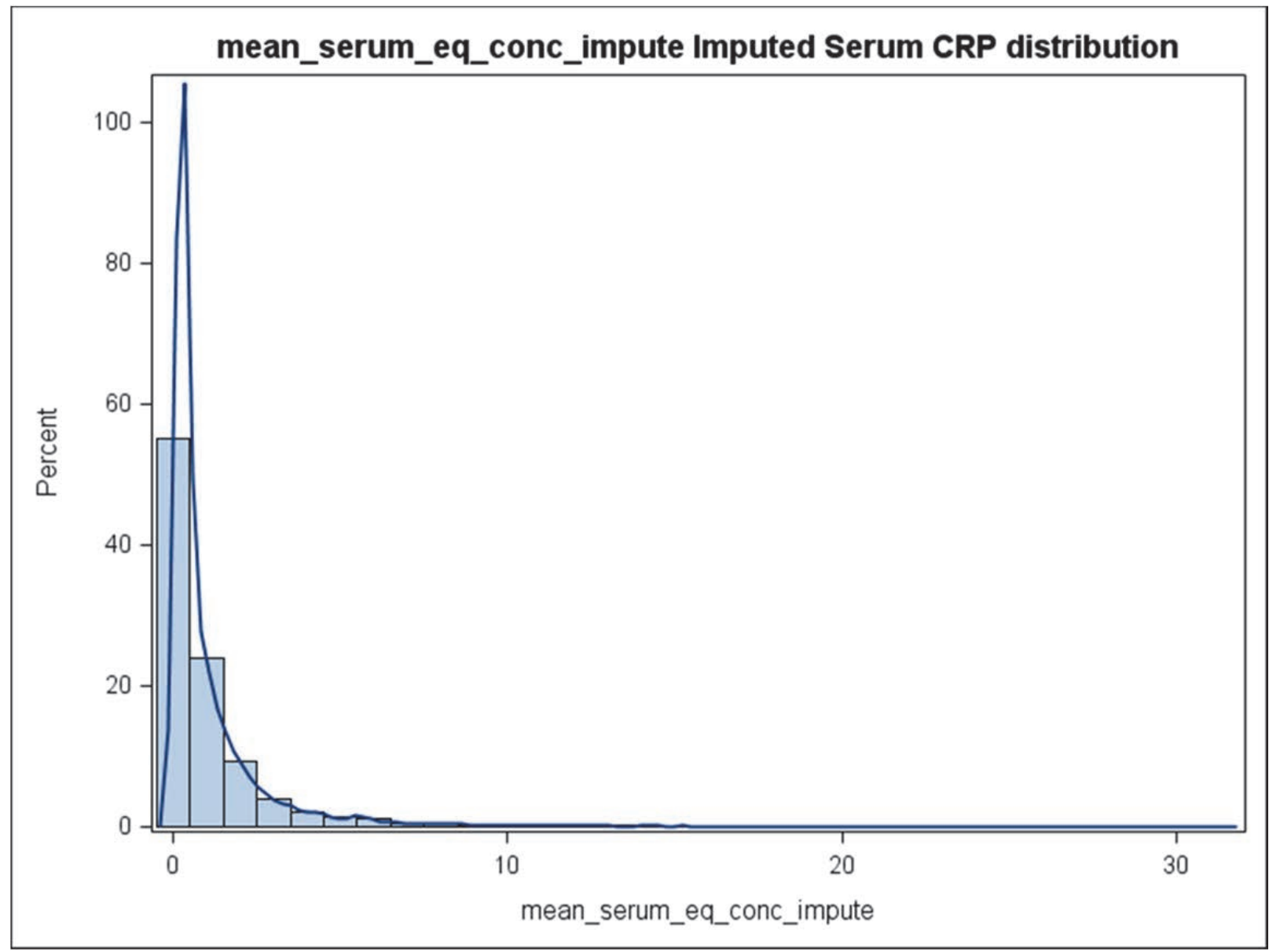


Figure 11 Mean logged serum-equivalent CRP distribution-with imputations

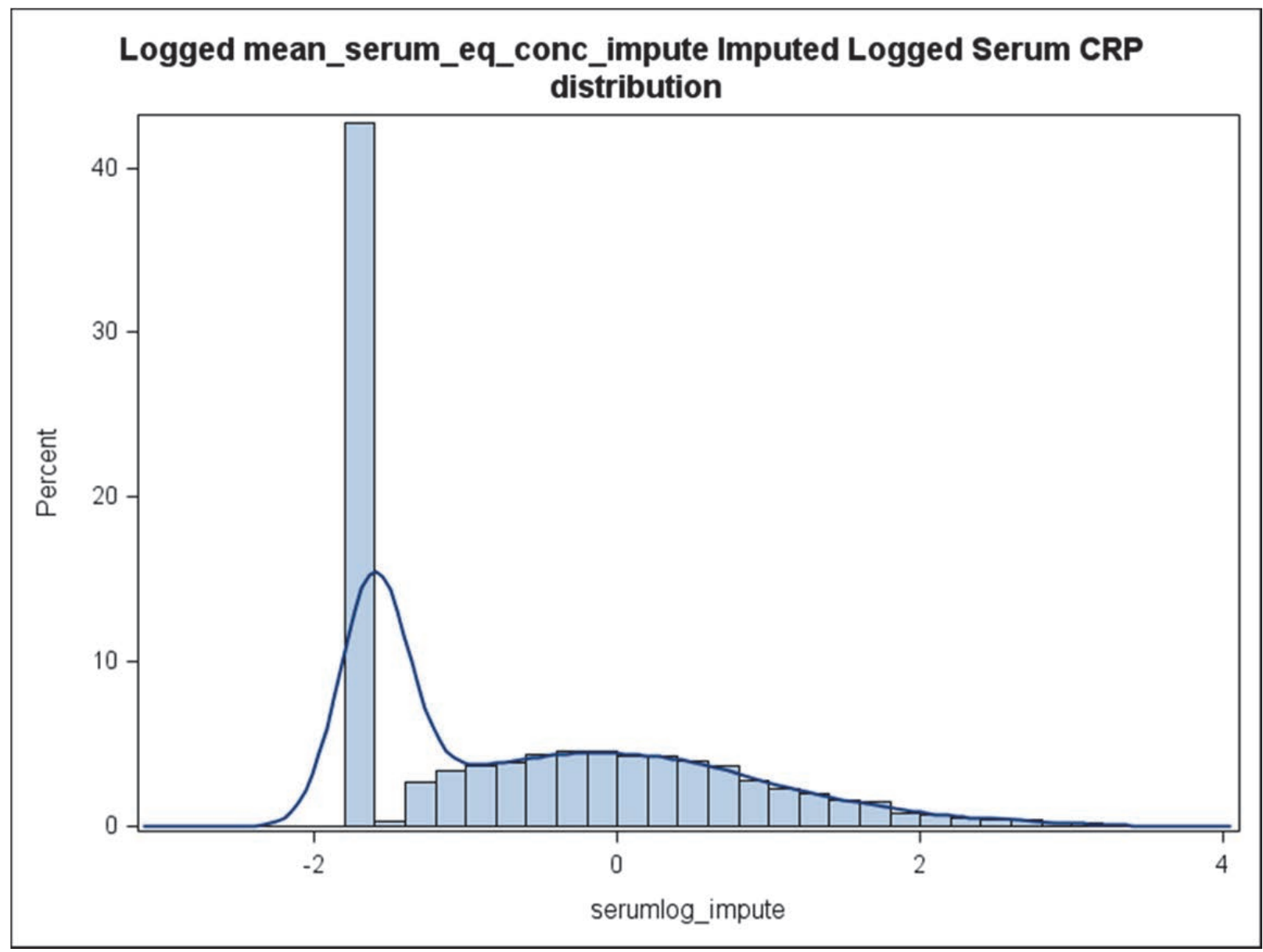




\section{References:}

McDade TW, Burhop J, Dohnal J. High-sensitivity enzyme immunoassay for C-reactive protein in dried blood spots. 2004. Clin Chem. 50:652-654.

Singh T, Newman AB. Inflammatory markers in population studies of aging. Ageing Res Rev. 2011. doi: 10.1016/j.arr.2010.11.002. 